This paper was published in the Journal of Beliefs \& Values, 29(3):252-261, 2008, as

\title{
Impacting teachers' and students' spiritual well-being.*
}

by J.W. Fisher

School of Education, University of Ballarat, Ballarat, Australia

Abstract:

Spiritual well-being (SWB) is reflected in the quality of

relationships that people have with themselves, others, environment and/or God.

This paper ties together several studies of SWB among teachers and students in primary and secondary, state, Catholic, other Christian, and independent schools in Victoria, Australia.

Teachers' lived experiences have greatest impact on their perceptions of help provided by schools for students' SWB.

Factors other than teachers contribute most to students' SWB.

As well as presenting an overview of key supports for students' SWB this paper reports ways in which spiritual dissonance can be identified. These findings could be used to lay a foundation for further support in nurturing the total well-being of staff and students in schools.

Keywords: help for spiritual well-being; spiritual dissonance; SHALOM

Corresponding author. Email: j.fisher@ballarat.edu.au

*This paper derived from a presentation at ISREV XVI, Ankara, Turkey 27 July - 1 August 2008 


\section{Introduction}

'Who are you?' and 'How are you?' Answers to these two questions will have major impact on your quality of life and the influence you have on others'.

When considering a response to the second question, we could address the many facets of health in turn. Health comprises physical, mental, emotional, social, vocational and spiritual components (Hawks 2004). The first five components are addressed in bio-physical psycho-social models of health. But, what is the spiritual component?

An answer to this question is embedded in the 'Who are you?' above. It reaches to the very core, we could say 'heart', of being human. People's socially-constructed beliefs and world-views filter their understanding of issues which impinge on their identity (Poll \& Smith 2003). The basic questions of meaning, purpose and values comprise the core of discussions on Personal spiritual well-being (SWB) (Seidl 1993).

Few people attempt to live as ascetics, separating themselves from others. The rest of us live with other people who influence, and are influenced by, us, whether in families, communities or nations. Some of the relationships formed here are weak, others are strong, as are the influences on and by other people. Our notions of morality, culture, and, for those for whom it is important, religion, build on and build up the Personal SWB, in what is called Communal SWB. For many people, these two domains are what they believe they need for SWB (Faver 2004).

Going beyond care, nurture and stewardship of the physical to a sense of relating, or connecting, with the environment is of paramount importance for indigenous people in developing their sense of identity and community. This mystical relationship is becoming increasingly valued by others, for Environmental SWB (Irvine \& Warber 2002).

Going a step further, into the unseen realms, many people, by faith, believe there is either an impersonal cosmic force or ultimate concern, or a personal Transcendental reality, often called God, which/who superintends the whole of Creation. Relating in this 
Transcendent realm should build on and build up the other three sets of well-being, for Transcendental SWB (progressive synergism described in Fisher 1998)

These four sets of relationships arose as key features of SWB from interviews of nearly 100 educators in schools in Victoria, Australia (Fisher 1998). This four domains model of Spiritual Health/Well-being has parallels in the NICA definition (1975) and work by Nye (Hay \& Nye 1998).

Spiritual well-being is reflected in the quality of these four sets of relationships, which reveal the underlying state of spiritual health of a person. People have varying beliefs and world-views so they will embrace these four sets of relationships to varying extents.

Any attempt to determine or measure the 'average' state of spiritual well-being for a population is fraught with challenge (Moberg 2002). In order to circumvent this challenge, a novel approach was taken in research reported here. Instead of comparing norms for groups, each person was asked what they thought was 'ideal' for spiritual well-being. This became the standard against which their 'lived experience' (how they felt) was measured to determine the degree of harmony or dissonance in each of the four domains of SWB.

For example, a full spectrum of views is provided in the literature in discussions about spirituality and religion - from spirituality as a subset of religion (religious view) (Hill et al. 2000), through the equivalence of the two constructs (Gorsuch \& Walker 2006), to religion as one expression of spirituality (Nolan \& Crawford 1997), to the other end that claims a spirituality devoid of religion (humanistic view) (Newby 1996). Some religions do not invoke the notion of a god (e.g. Buddhism). Other religions include relationship with a Transcendent Other /God. If people do not believe a god is important for their ideal of SWB (e.g., atheist/ agnostic or non-theist), when they do not report a lived experience with a god, they are in tune with their ideals, i.e., no spiritual dissonance for them in this domain.

When studying students' well-being in schools, what is the focus? In our western, materialistic society, we most frequently equate school success or 'health' with academic 
grades. Thanks to Descartes, we shoot straight for the head, often ignoring the heart, or spiritual well-being.

Just as health is multifaceted, so too is well-being. It is seen as the outworking or reflection of the state of health (Ellison 1983). When a person (either teacher or student) is physically unwell, it is generally obvious. When they bring psychological, emotional, social or spiritual baggage to school, these can often go unnoticed. Such baggage is, however, likely to prevent the full involvement of each person in processes of learning until dealt with.

Indicators and indices of child well-being in the United States contain very little in the way of spiritual well-being. Only one survey method devotes three of its 36 items to a measure of emotional/spiritual well-being. The three questions relate to suicide rate, weekly religious attendance and religion rated as very important (Land, Lamb \& Mustillo 2001; Land, Lamb et al. 2007). This is a prime case of equating religion with spirituality.

Recent reports have mentioned 'positive relationships with parents and siblings and positive attitudes towards school and community (Lippman 2007, 49). These constructs concur with some of the matrix of support for students developed via the Quality Of Life Influences Survey (QOLIS) (Fisher 2006), but Lippman et al. did not relate their findings to spiritual well-being, only to physical, psychological, cognitive, social and economic wellbeing.

This presentation ties together several studies in which views about spiritual wellbeing were investigated among teachers and students in primary and secondary, state, Catholic, other Christian, and independent schools in Victoria, Australia (Fisher 1999, 2004, 2006, 2007). As well as presenting an overview of key supports for students' SWB it shows some ways in which spiritual dissonance can be identified. These findings could be used to lay a foundation upon which further support might be built to nurture the total well-being of staff and students in schools. 


\section{Method}

The Spiritual Health And Life-Orientation Measure (SHALOM) (Fisher 1999; Gomez \& Fisher 2003) was used to ascertain 820 teachers' views in three categories, showing how important relationships are for i) an ideal state of SWB; ii) reflecting teachers' lived experiences; and iii) showing how well teachers think schools help students develop SWB (Fisher 2007). SHALOM comprises 20 items, five representing each of the four domains of SWB mentioned above (e.g., identity, love people, connect with nature, relate with God). Items are scored on 5-point Likert scale ( $1=$ very low to $5=$ very high $)$.

Secondary school students $(\mathrm{n}=1002)$ also completed 'ideal' and 'lived experiences' categories of SHALOM. Primary school pupils $(n=372)$ completed Feeling Good, Living Life (FGLL), a 16-item measure of SWB, with four items in each of the four domains (e.g., feel happy, love family, watch sunset, know God as friend). FGLL is scored on a 5-point Likert scale (YES yes ? no NO) (Fisher 2004). These surveys were completed in class under teachers' supervision, following ethics' approvals.

All students also completed the Quality Of Life Influences Survey (QOLIS) (Fisher 2006). QOLIS elicits students' responses about how much 22 influencers (from school, family, friends and church) help them relate with themselves, others, nature, and God. A 3point Likert scale was used $(0=$ never to $2=$ always $)$.

Secondary students responded to the Oxford Happiness Inventory (OHI) (Argyle \& Hills 2000) and the Junior Eysenck Personality Questionnaire Revised-Abbreviated (JEPQRA) (Francis 1996).

\section{Results}

\section{Levels of spiritual well-being}

Teachers 
Teachers' levels of lived experience in each of the four domains of SWB remained fairly constant from primary through to senior secondary levels, within each of the four different types of schools. However, slight variations existed between school types (Fisher 2007). Some Christian school teachers rated their lived experiences slightly lower than others on Personal SWB (at junior secondary) and Communal SWB (at primary and junior secondary) and they scored lower than others on Environmental SWB (at primary to senior secondary). It was not surprising to note that Christian school teachers also rated their lived experience higher than others on Transcendental SWB, with staff from secular state schools lowest. (Figure 1 shows a selection of the statistics fully reported in Fisher 2007, 169).

Fig. 1. primary , junior \& senior secondary Teachers' and Students' SWB \& Teacher help PERsonal \& TRAnscendental SWB

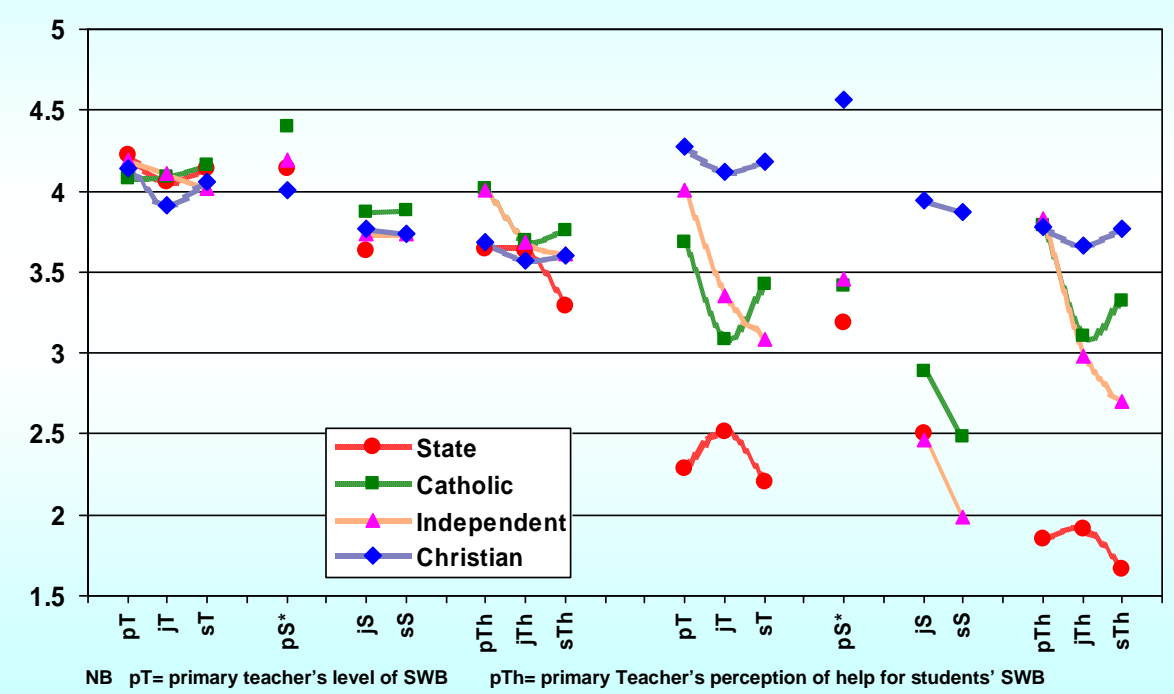

Primary school pupils

Catholic primary school pupils rated Personal SWB higher than others. Results for the Communal domain (relating with family) were tightly grouped at a very high level for primary pupils. Results for Environmental SWB were similar for pupils in each type of 
school. Christian primary school pupils rated themselves higher than others on relating with God (Transcendental SWB).

Secondary school students

Close agreement was shown on Personal and Communal SWB by secondary students in the four types of school (Fisher 2006, 352). Christian school students rated Environmental SWB slightly lower than others and Transcendental SWB markedly higher.

\section{Comparing teachers' with students' levels of SWB}

Primary pupils' levels of SWB could not be compared directly with teachers' because different measures were used to assess their SWB.

As SHALOM was used with teachers as well as secondary school students, direct comparison was possible. A fairly consistent pattern was noticed, with teachers generally rating levels of SWB higher than students in each of the four domains of SWB. However, at junior secondary level, teachers and students rated their SWB similarly in Christian schools for Communal SWB, and in Catholic and Christian schools for Transcendental SWB.

\section{Influences on teachers' perceived help for SWB}

Linear regression analyses reveal that teachers' lived experiences account for greatest variance in their perceptions of help provided for students' SWB in schools (see Table 1 for detail).

Table 1. Factors influencing Teachers' perceptions of Help for Students' SWB in schools

\begin{tabular}{|c|c|c|c|c|}
\hline Factor $\backslash$ domain SWB & Personal & Communal & Environmental & Transcendental \\
\hline$\Delta \mathrm{R}^{2}$ & .27 & .43 & .41 & .45 \\
\hline School level (prim-sec) & -.07 & -.15 & -.13 & -.10 \\
\hline $\begin{array}{l}\text { School type } \\
\text { Ideals }\end{array}$ & .09 & & .22 & .24 \\
\hline Lived experience & .46 & .54 & .44 & .50 \\
\hline
\end{tabular}

Note: $\beta$-values shown from linear regression analyses 


\section{Comparing teachers' perceived levels of help with students' levels of SWB}

Teachers' perceptions of help provided by schools for students' SWB were remarkably similar to that of secondary students' lived experience in Personal, Communal and Environmental domains. Slight variations existed in Transcendental SWB with teachers in Catholic schools (at senior secondary), and independent schools (at junior and senior secondary), expecting schools to provide greater help than that experienced by their students. In state schools, junior secondary students reported higher lived experience of relating with God than teachers would anticipate schools providing. Only Christian school staff appeared to be in tune with their students here.

Differences between teachers' perceptions and students' experiences for Transcendental SWB could impact teaching of Religious Education.

\section{Discussion}

\section{Students' perceived levels of help for SWB}

Primary pupils and secondary school students provided information about how much help various groups provide for their SWB. Whilst analyzing this information from QOLIS, it became clear that pupils and students were helped in developing SWB by factors other than school.

Christian school students are more optimistic than others about help they receive from teachers and church for SWB generally, and by family and friends for relating with God, in particular.

Independent senior secondary school students report lack of support from school and church for nurturing SWB. They are more reliant on family and friends (especially for Personal and Communal SWB).

Catholic school students report levels of support for SWB in-between the other two. 
Linear regression analyses reveal that students' ideals, and their perceptions of how much they influence themselves, are major factors accounting for variance in students' lived experiences in four domains of SWB (see Table 2). It would be interesting to compare the impact of good and poor teachers on students' perceptions of support, to see if they are taking their teachers for granted.

Table 2. Factors which help build SWB in secondary school students ( $\beta$-values shown)

\begin{tabular}{|c|c|c|c|c|}
\hline Factor $\backslash$ domain SWB & Personal & Communal & Environmental & Transcendental \\
\hline$\Delta \mathrm{R}^{2}$ & .47 & .48 & .69 & .73 \\
\hline Gender & & .06 & & \\
\hline Importance of religion & & & & .21 \\
\hline Self & .22 & .15 & .21 & .21 \\
\hline Mother & & .08 & .02 & \\
\hline Female friend & .06 & & & \\
\hline God & & & & .16 \\
\hline Ideals & .60 & .59 & .67 & .36 \\
\hline
\end{tabular}

\section{Spiritual dissonance}

The notion of norms for samples is problematic. Some university reports provide norms for spirituality studies, but size of some samples does not warrant the claim of being representative of larger groups (see Bufford et al. 1991; Koenig et al. 2001 ).

The problem of norms can be circumvented by using each person as their own standard, by comparing their 'lived experience' with 'ideals.' The difference provides a measure of each person's level of harmony or dissonance within each domain of SWB. People who show dissonance in more than one of the four domains of SWB have been labeled 'spiritual dissonants,' because, as a group, they show significant variation from other people (Fisher 2007). 


\section{Teachers}

Results from these studies indicate that 12 percent of teachers showed dissonance in more than one of the four domains of SWB. These dissonants have significantly higher ideals than they are able to live up to. And, as teachers' lived experiences markedly impact their perceptions of help provided by schools, these dissonants have lower expectations of schools (especially for Personal, Communal and Environmental SWB), and therefore of themselves? If this is the case, these staff need guidance in setting more realistic goals and/or support in raising their own levels of lived experience for SWB.

Appropriate professional development would probably best be given one-to-one for dissonants, but this could be very time consuming. Alternatively, these staff could be set apart from involvement in nurturing students' SWB, but this could be difficult as teachers have responsibility for educating the 'whole' child.

It is not easy to pick spiritual dissonants by looking at a group of teachers, because they are not significantly different from others by gender, type of school, year level taught or subject specialty. The only apparent factor is that dissonants have a slightly higher percentage of teachers in their $40 \mathrm{~s}(21 \%)$, compared with other age groups $(7 \%$ for $20 \mathrm{~s}, 12 \%$ for $30 \mathrm{~s}$, $13 \%$ for $50+)($ Chi square $(3,796)=9.98, p=.019 ; \mathrm{phi}=.112, \mathrm{p}=.019)$. But, SHALOM can help identify dissonants.

\section{Students}

The same percentage of secondary school students as teachers (12\%) show dissonance in more than one domain of SWB.

Only $3.2 \%$ of primary pupils would be classified as 'spiritual dissonants' using FGLL. With tight constraints (e.g., ethics' approval from university, school authorities, parents and pupils) it would not be surprising to find that this sample was a rather select group. Further study is needed with a greater diversity of primary pupils to see how representative this group 
was, and to show how well it compares with SHALOM in revealing spiritual dissonance among young children. The number of primary school dissonants ( $\mathrm{n}=12$ out of 372$)$ was too small to do comparative statistical analyses.

Secondary school dissonants ( $\mathrm{n}=118$ out of 998$)$ showed marked differences from the remaining students. There were no differences by gender, level or type of school, but they did score lower on the Oxford Happiness Inventory (Chi-square $(1,998)=17.6, \mathrm{p}<.001$; phi=-.133, $\mathrm{p}<.001$ ) and they scored higher on the Psychoticism scale of the JEPQR-A (but not Extraversion or Neuroticism) (Francis 1996) (Chi-square $(1,998)=16.7, \mathrm{p}<.001$; phi=.129, $\mathrm{p}<.001)$. Independent t-tests showed that student dissonants had higher ideals and lower lived experiences (how they feel) in each of the four domains of SWB. This would not make them happy (OHI), possibly even depressed. Dissonants also gave lower ratings to the help they receive for SWB from themselves, God, mother and father (see Figure 2). Eysenck (1993) states that higher psychoticism scores correlate with tough-mindedness and traits such as nonacceptance of cultural norms, immaturity and anti-authoritative attitudes. But, he also linked these scores with higher creativity. It would be interesting to identify such students to see how they fit academically, socially and emotionally in the school environment, at home, as well as future workplace, and see if, and how, counseling influences their lives.

Fig. 2. Spiritual dissonance among secondary students ( $Y=$ yes $N=$ no)

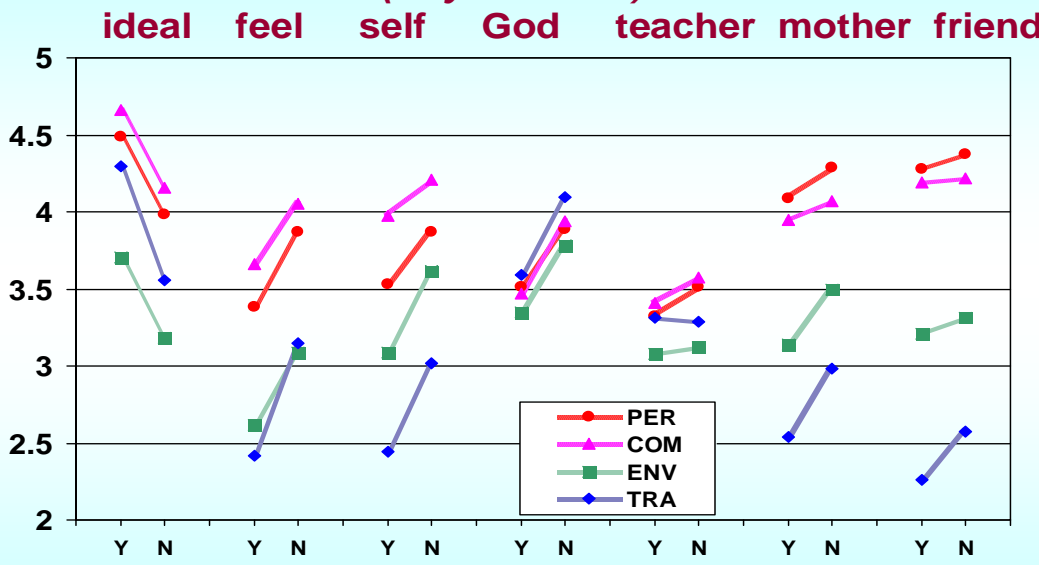


Student dissonants did not rate help received from (and therefore authority of?) teachers or religious leaders any differently than other students. If RE classes teach about God, dissonants would probably not handle this any differently than other students. It is only in relating with God that differences could arise.

\section{Summary}

Teachers' lived experiences have greatest impact on their perceptions of help provided by schools for students' SWB. Teachers generally rate lived experiences of SWB higher than students. However, teachers' perceptions of their help are a good match with students' lived experiences for Personal, Communal and Environmental SWB, at primary and junior secondary levels of schooling.

Less clarity is shown in teachers' judgment on Transcendental SWB. Catholic and independent school teachers rate schools' help higher than students' reported lived experience in relating with God. State school teachers rate their schools' help below the level of students' lived experience in this area. Only Christian school teachers appear to be in tune with their students here. These variations could impact teaching of RE in different schools.

Factors other than teachers contribute most to students' SWB. Students' ideals, and how they think they support themselves, have greatest influence on their SWB. For teachers to impact students' SWB, they need to input into students' ideologies and support their relationships with self, others, nature and/or God, whether or not the students acknowledge it. To effect this, teachers must know themselves, their students and their subject matter well.

SHALOM, FGLL and QOLIS are useful tools for teachers to gain understanding of their own and their students' SWB, which should help inform appropriate learning and counseling experiences to nurture them on their spiritual journeys. 


\section{References}

Argyle, M. \& P. Hills. 2000. Religious experiences and their relations with happiness and Personality. The International Journal for the Psychology of Religion. 10, no.3: 157172.

Bufford, R.K., R.F. Paloutzian, \& C.W. Ellison. 1991. Norms for the Spiritual Well-Being Scale. Journal of Psychology \& Theology. 19, no.1: 56-70.

Ellison, C. 1983. Spiritual well-being: Conceptualization and measurement. Journal of Psychology and Theology. 11, no.4: 330-340.

Eysenck, H.J. 1993. Creativity \& Personality: Suggestions for a theory. Psychological Inquiry. 4: 147-178.

Faver, C.A. 2004. Relational Spirituality and Social Caregiving. Social Work. 49, no.2: 241249.

Fisher, J.W. 1998. Spiritual health: its nature and place in the school curriculum. PhD diss., University of Melbourne (http://eprints.unimelb.edu.au/archive/00002994/)

----- 1999. Developing a spiritual health and life-orientation measure for secondary school students. Paper presented at University of Ballarat Annual Research Conference, 15 October, pp. 57-63, Ballarat, Australia.

------. 2004. Feeling Good, Living Life: a spiritual health measure for young children. Journal of Beliefs \& Values. 25, no.3: 307-315.

-----. 2006. Using secondary students' views about influences on their spiritual well-being to inform pastoral care. International Journal of Children's Spirituality. 11, no.3: 347356.

-----. 2007. It's time to wake up and stem the decline in spiritual well-being in Victorian schools. International Journal of Children's Spirituality. 12, no.2: 165-177.

Francis, L.J. 1996. The Development of an Abbreviated Form of the Revised Junior 
Eysenck Personality Questionnaire (JEPQR-A) among 13-15 year-olds. Personality and Individual Differences. 21, no.6: 835-844.

Gomez, R. \& J.W. Fisher. 2003. Domains of spiritual well-being and development and validation of the Spiritual Well-Being Questionnaire. Personality and Individual Differences. 35, no.8: 1975-1991.

Gorsuch, R.L. \& D. Walker. 2006. Measurement and Research Design in Studying Spiritual Development. In Handbook of Spiritual Development in Childhood and Adolescence, eds. E.C. Roehlkepartain, P.E. King, L.M. Wagener \& P.L. Benson, 92-103. Thousand Oaks, CA: Sage Publications.

Hawks, S. 2004. Spiritual Wellness, Holistic Health, and the Practice of Health Education. American Journal of Health Education. 35, no.1: 11-16.

Hay, D. \& R. Nye. 1998. The spirit of the child. London: Fount.

Hill, P.C., K.I. Pargament, R.W. Hood, J.P. McCullough, D.B. Swyers, D.B. Larson \& B.J. Zinnbauer. 2000. Conceptualizing Religion and Spirituality: Points of Commonality, Points of Departure. Journal for the Theory of Social Behavior. 30, no.1: 51-77.

Irvine, K.N. \& S.L. Warber. 2002. Greening healthcare: Practicing as if the natural environment really mattered. Alternative Therapies in Health and Medicine. 8, no. 5: 76-83.

Koenig, H.G., M.E. McCullough \& D.B. Larson. 2001. Handbook of Religion and Health. Oxford: Oxford University Press.

Land, K.C., V.L. Lamb \& S.K. Mustillo. 2001. Child and Youth Well-being in the United States, 1975-1988: Some findings from a new index. Social Indicators Research. 56, no. 3: 241-320.

Land, K.C., V.L. Lamb, S.O. Meadows \& A. Taylor, A. 2007. Measuring Trends in Child 
Well-being: An evidence-based approach. Social Indicators Research 80, no.1: 105132.

Lippman, L.H. 2007. Indicators and Indices of Child Well-being: A brief American history. Social Indicators Research. 83, no.1: 39-53.

Moberg, D.O. 2002. Assessing and Measuring Spirituality: Confronting Dilemmas of Universal and Particular Evaluative Criteria. Journal of Adult Development. 9, no.1: 47-60.

National Interfaith Coalition on Aging. 1975. Spiritual well-being: a definition. Athens, Ga.: Author (NICA).

Newby, M. 1996. Towards a secular concept of spiritual maturity. In Education, Spirituality and the Whole Child, ed. R. Best, 99-107. London: Cassell.

Nolan, P. \& P. Crawford. 1997. Towards a rhetoric of spirituality in mental health care. Journal of Advanced Nursing 26: 289-294.

Poll, J.B. \& T.B. Smith. 2003. The Spiritual Self: Toward a Conceptualization of Spiritual Identity Development. Journal of Psychology and Theology. 31, no.2: 129-142.

Seidl, L.G. 1993. The value of spiritual health. Health Progress. 74, no. 7: 48-50. 